\title{
Following the trail of crumbs: A bibliometric study on consumer behavior in the Food Science and Technology field
}

\author{
Márcia-Gabriela C. Kasemodel ${ }^{\mathrm{a}}$, Fausto Makishi ${ }^{\mathrm{a}}$, Roberta C. Souza ${ }^{\mathrm{b}}$, And \\ Vivian-LARA SiLVA ${ }^{*}$

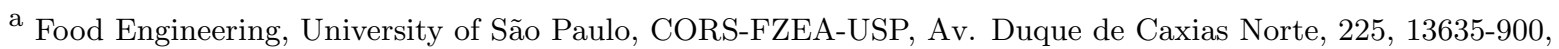 \\ Pirassununga (SP), Brazil \\ b Industrial Engineering Dep., Polytechnic School, University of São Paulo, CORS-PRO-POLI-USP, Av. Prof. \\ Luciano Gualberto, 380, 05508-010, São Paulo (SP), Brazil \\ ${ }^{c}$ Food Engineering Dep., University of São Paulo, CORS-FZEA-USP, Av. Duque de Caxias Norte, 225, \\ 13635-900, Pirassununga (SP), Brazil \\ ${ }^{*}$ Corresponding author \\ vivianlara@usp.br \\ TEL: $+55-19-3565-4160$
}

Received: 5 May 2015; Published online: 18 April 2016

\begin{abstract}
The main goal of this paper was to conduct an exploratory study regarding consumer preference in the field of Food Science and Technology. Two questions guided this study: Is it possible to identify a trail of crumbs concerning consumer behavior in the Food Science and Technology field? And, if that trail exists, where is it leading academia in terms of research trends of interest? A bibliometric study was conducted using an analysis software called CiteSpace. The use of this methodology ensured the impartiality of the literature review of the topic of interest. A survey of all articles indexed in Web of Science between 1993 and 2013 regarding consumer behaviour was carried out. In total, 1,786 articles were analyzed. The recent increased concern regarding consumer behavior was evident. With the USA and Spain having a significant role in driving the trail. Eight other countries that exhibited similar influences are: Italy, England, Australia, Germany, Denmark, France, Netherlands and Brazil. The research trends observed were grouped into seven major hot topics: sensory, health, safety, willingness to pay, packaging, ethics, and lifestyle/convenience. However, the development of publishing trends depended on where the research was carried out. A final suggestive finding, demonstrated that scientific knowledge does not occur in a vacuum.
\end{abstract}

Keywords: Quantitative Analysis; Web of Science; CiteSpace; Publishing Trends

\section{Introduction}

It seems difficult to track the direction of scientific knowledge in any given area. This difficulty arises from the unpredictable nature of the development of scientific knowledge, built as it is from models, theories, and accumulated experiences that intertwine and create solutions for a wide variety of challenges. This statement is par- ticularly relevant in the area of Food Science and Technology, given the impressive speed of its development in recent years.

Inspired by this "opportunity", Bruin and Jongen (2003) and Aguilera (2006) discussed current trends in consumption patterns and their effect on the processes of knowledge development, both in industry (trends in research and development of new products), and in academia (trends in 
publication). The discussion is quite suggestive, highlighting both the growing interest in consumer behavior in the Food Science and Technology field.

The authors' insights nevertheless are based on personal impressions and experiences (Bruin \& Jongen, 2003), as well as on a bibliographic review, referring to papers published in scientific conferences in the field (Aguilera, 2006).

With this in mind, the main goal was to contribute to this debate by using a systematic analysis (using the methodology of bibliometric study) of publications in the area of Food Science and Technology, through the consideration of journals indexed in the Web of Science database during the past 20 years (1993-2013).

Two main questions were of particular interest:

1 Is it possible to identify a trail of crumbs concerning consumer preference in the Food Science and Technology field?

2 If that trail exists, where it is leading us in terms of research trends of interest (hot topics)?

\section{Materials and Methods}

The bibliometric study methodology developed by Presoto, Souza, and Thurler (2013) was used to carry out the quantitative analysis of literature using methods and objective instruments that were replicable and consistent for obtaining and describing scientific production on the topic under study (Thanuskodi, 2010).

Presoto et al. (2013) method was used to structure the process of bibliometric analysis. The authors mapped scientific articles in ISI Web of Science, and used tools available in the same database, as well as in the CiteSpace software, in order to conduct both quantitative analysis and inquiry into the trends and patterns of scientific production that were being investigated.

The Web of Science is an American database owned by the Thomson Reuters Group that is dedicated to indexing information from global publications which are influential, relevant, and reliable (Gall, Millot, \& Neubauer, 2009).

CiteSpace is a bibliometric analysis software program, in which the primary source of input data is Web of Science. The software was used to create and analyze networks derived from articles, allowing the evaluation of trends in a given field of research (Chen, 2006). CiteSpace reduced the researcher's influence in conducting the analysis, especially concerning the selection and exclusion of articles in the literature review. Thus, CiteSpace ensured a systematic analysis, increasing the transparency and reliability of results (Presoto et al., 2013).

The analysis procedure adopted, consisted of three main steps:

1 Research mapping;

2 Quantitative analysis; and 3. Analysis of trends and patterns.

For the research mapping step, a survey was conducted to cover all articles indexed in Web of Science between 1993 and 2013 regarding consumer behavior. The following keywords were used: "consumer* behavior*", "consumer* behaviour*", "consumer* preference*", "consumer* perception*", "consumer* attitude*", and "consumer* acceptance*". This resulted in an initial selection of 14,876 articles.

This selection was refined by using three Web of Science filters: Publication years (1993-2013); Web of Science Categories (Food Science and Technology); and Document Type (Articles). This reduced the list to 1,786 results, which was taken as the sample of interest in the bibliometric study regarding consumer behavior.

The second step consisted of a quantitative analysis. The tools available on Web of Science were used to categorise the list of articles according to the article's year of publication, country, journal, and institution.

The third step consisted of identification of the existence of trends and patterns concerning the interest of the Food Science and Technology field in consumer behavior.

A database was constructed to extract material from each of the 1,786 previously selected articles by using the 'save function' available on Web of Science. The files were saved in Plain Text format to be compatible with CiteSpace. 'Full record' and 'cited references' options were selected, taking into account each article's title, authors, addresses, abstract, keywords, and 
references. From the database, visualization and analysis of trends and patterns was possible through the construction of 'visualization graphs' in CiteSpace.

Visualization graphs consist of clusters in which articles are categorized according to preestablished criteria, mainly 'time slicing' and 'node types'.

Time slicing is a tool that can configure the time span that CiteSpace will analyze, and divide the selected period of time into a series of smaller windows (Chen, 2004). Different time slices were represented by a range of colors (Chen, 2004). For this study, each color represented a year in the period from 1993 to 2013. Tones of blue and red represented, the oldest and most recent articles respectively.

The second tool, node types, allowed the categorization of articles selected according to nine different options: country, author, cited author, keyword, term, category, institution, cited reference, and cited journal. Considering the specific goals of this bibliometric study, the nodes of country, institution, and keywords were noted to be of most interest and significance. The size of a node is associated with the frequency of publications. The larger the node, the greater the number of articles contained in it. Similarly, the larger the font size used for naming the node, the greater the number of articles related (Chen, 2004).

\section{Results and Discussion}

\subsection{Evolution of the Food Science and Technology field's interest in consumer behavior}

The data demonstrated a positive growth trend in the number of articles over the last 20 years, from 1993 to 2013 (see Figure 1). In 1993, a discrete amount of 12 articles that directly addressed consumer behavior were published in the field of Food Science and Technology, which was equivalent to $0.2 \%$ of all papers published in the field that year $(6,391)$. Twenty years later, a relative increase was seen, and a total of 218 articles that addressed aspects of consumer behavior were published in 2013, which represented approximately $1.1 \%$ of the total of papers published in the field $(19,599)$. Although apparently modest, the growth rate of articles regarding consumer behavior was $1.717 \%$, equivalent to an approximate 2.3 -fold increase when compared to the field's overall growth rate.

The observed growth regarding the Food Science and Technology field's interest in consumer behavior was mainly achieved in USA and Spain (Figure 2). Together, both countries accounted for $38.13 \%$ of articles considering consumer behavior in the field of Food Science and Technology during the period. Another eight countries presented a similar level when combined $(38.18 \%)$ over the past 20 years. The countries in question were Italy, England, Australia, Germany, Denmark, France, Netherlands, and Brazil.

Although (Figure 2) shows us the ranking of countries according to total number of articles, it does not allow the visualization of the increase in scientific production through time.

To do so a visualization graph using CiteSpace was constructed (Figure 3). It should be noted that all countries present an increase in the number of articles over the 20-year period. This is shown with the blue-green color at the center of the graph (representing older publications), versus the red hue at the extremities (referring to more recent articles). Once again, USA and Spain are prominent in comparison to the other top 10 countries, as observed by the size of the cluster and font.

Additionally, the visualization graph enabled the observation of the collaboration between countries. Countries linked to one another indicate co-authorship at a national level (Figure 3). While USA and Spain present collaboration, Mexico and Argentina are countries that do not have instances of co-authorship regarding consumer behavior, since they do not present links as shown in Figure 3).

Having observed the growing interest of the Food Science and Technology field in consumer behavior over the last 20 years in distinct countries, it was possible to go further in detailing the major contributors in terms of journal and research institutions.

Table 1 described a ranking of journals according to number of published articles. Journals with 
$76 \mid$ Kasemodel et al.

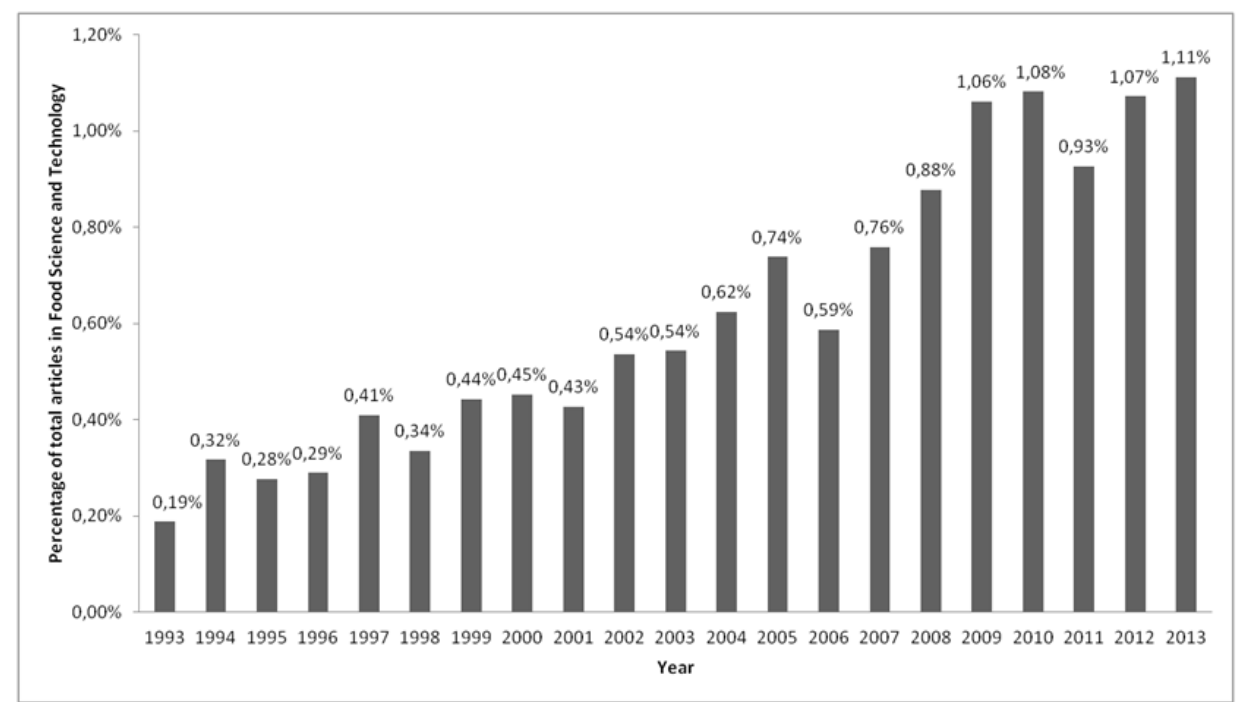

Figure 1: Evolution of the number of articles in which terms related to consumer behavior are directly cited

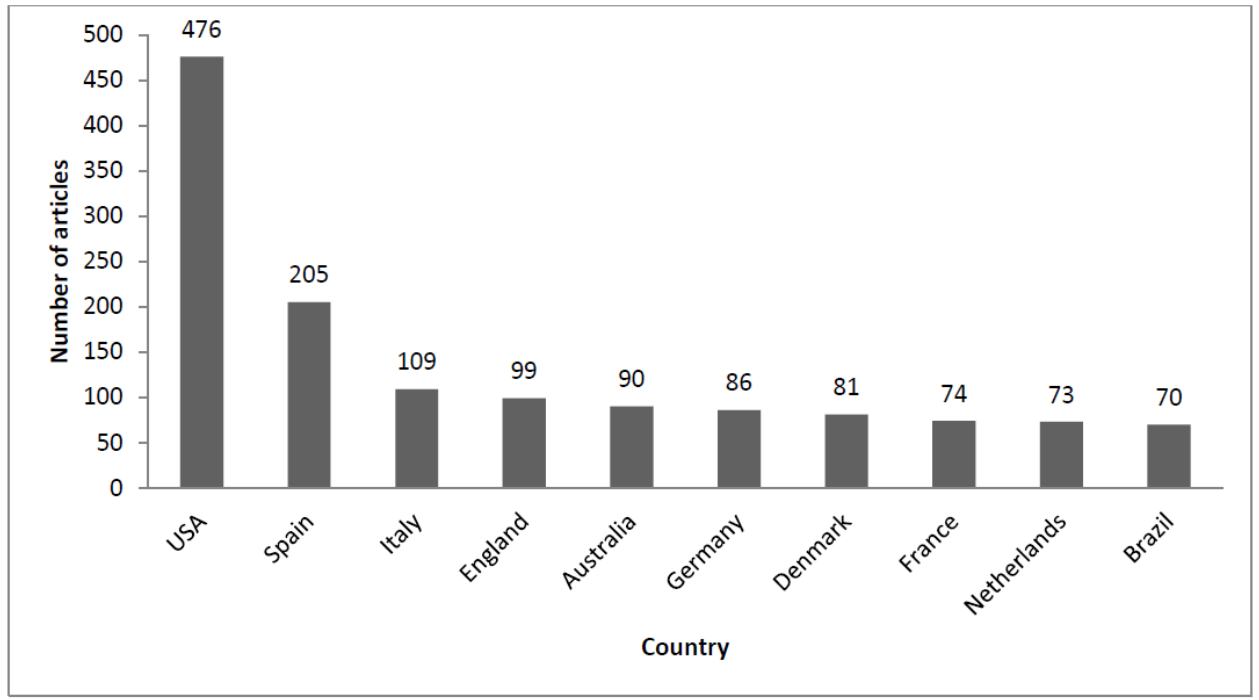

Figure 2: Top ten countries by number of articles which directly cite terms related to consumer behavior 


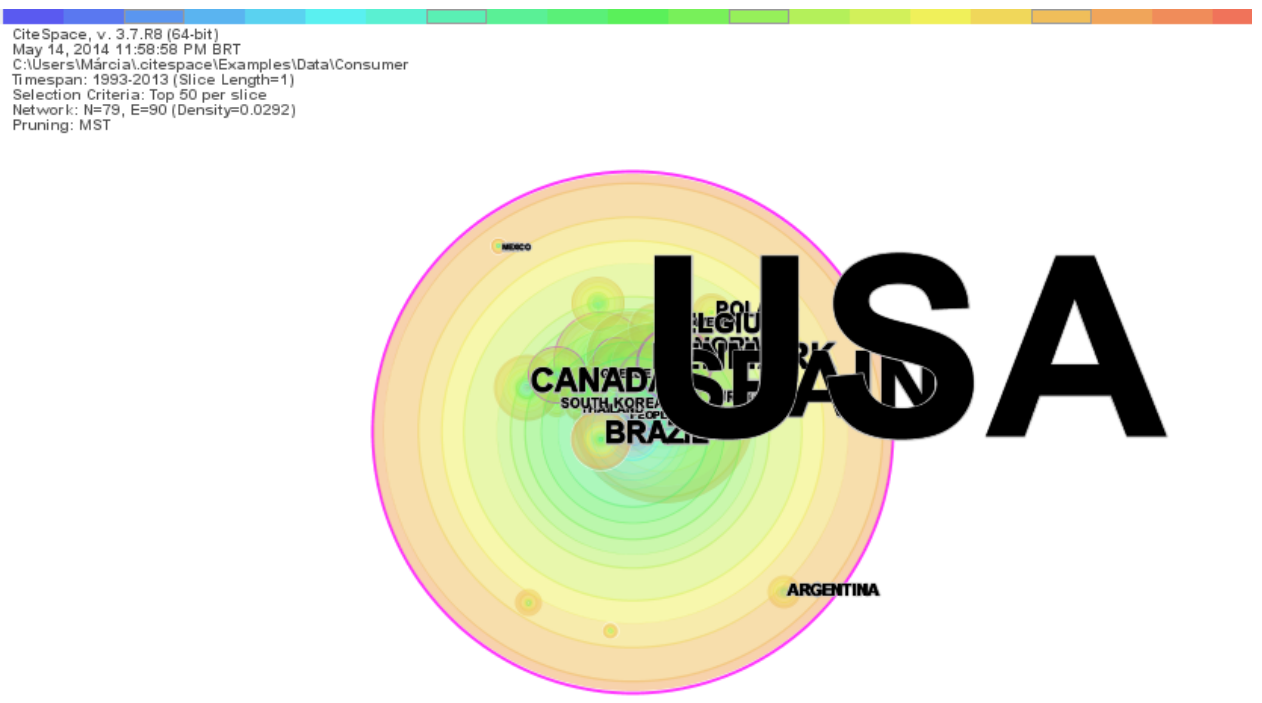

Figure 3: Visualization graph

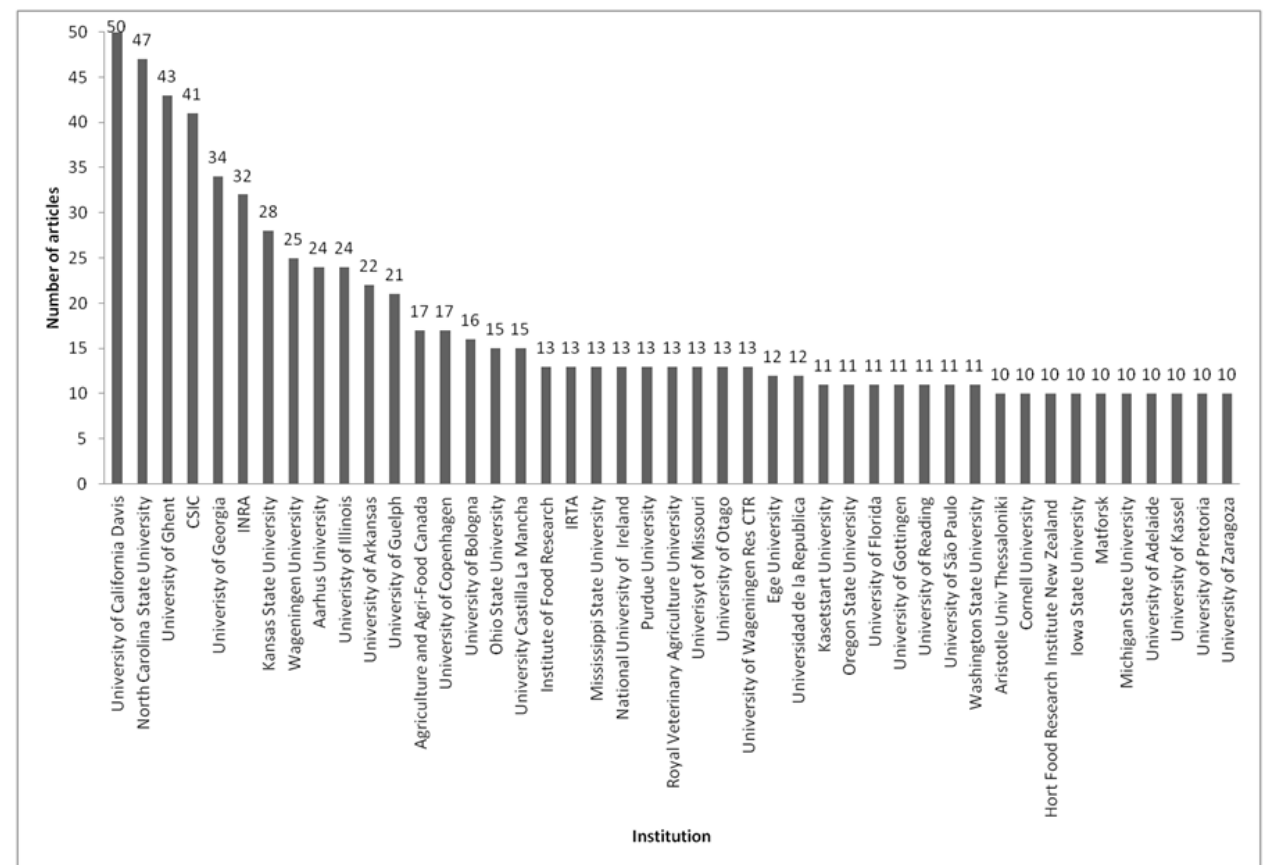

Figure 4: Institutions with the highest number of articles 
10 or more articles regarding consumer behavior were selected. In total, Table 1 lists 38 journals, of which 15 have an impact factor greater than 2.0. This could be suggestive, since journals of high scientific relevance also seem to be interested in the topic.

Overall, Table 1 reflects the high concentration of publications in a small number of journals. Indeed, the 3 most relevant journals account for over $30 \%$ of publications. At the same time, Table 1 indicated that there existed a wide range and heterogeneity in editorial lines, which allowed the implication of the importance of consumer studies for different segments of the food industry, such as meat, dairy, and cereal.

A similar result was verified when considering the institutions most relevant to this field of research. Figure 4 ranked institutions with the highest number of published articles and indicated that the University of California and North Carolina State University had the most significant number of publications, with 50 and 47 respectively.

\subsection{Food Science and Technology field's patterns on consumer behavior}

Over the last twenty years, data collected and subjected to quantitative analysis regarding annual article publications by country, journal, and research institution showed there has been an increase in the level of interest in this theme.

Such evidence prompted focus on the issue whether it was possible to identify converging patterns in Food Science and Technology concerning consumer behavior. The bibliometric study showed that this was the case.

The systematic analysis of the 1,786 articles selected led to identification of seven hot topics, which were considered drivers of research related to keywords or terms with highest occurrence among article titles, abstracts, and keywords, (Table 2).

The seven hot topics were: sensory, health, safety, willingness to pay, packaging, ethics, and lifestyle/convenience. Hot topics were categorized based on their global importance in terms of volume, this led to the establishment of a general pattern concerning drivers of research (Figure 5). This pattern demonstrated that, among all hot topics, sensory was considered the most relevant, with 980 articles, followed by health with 614 articles. Safety and willingness to pay came in third and fourth, accounting for 348 and 329 articles respectively. As for packaging, ethics, and lifestyle/convenience, these hot topics represented 239, 208, and 196 articles.

The "sensory" hot topic occured in 980 articles that refered to sensory attributes of a certain food or beverage, such as flavor, odor, texture, and appearance (Grunert, 2006). This made "sensory" the hottest topic globally when considering consumer behavior in the field of Food Science and Technology. This finding was justified since sensorial studies are technical and have attributes that are measurable by the consumer through sensory analysis.

The topic "health" was ranked as the second most relevant in terms of volume of articles published globally. With 614 articles containing keywords such as diet, obesity, nutrition, and functional food, this hot topic is becoming more relevant in view of increasing education levels and the availability of information. Furthermore, the discovery of components in foods that promote health assign greater importance to this category, according to Bruin and Jongen (2003). However, many effects of food on health are not measurable by the consumer, such as the risk factor of certain diseases, especially when the probability is low (Grunert, 2006).

Concerning "safety", this hot topic was considered the third most relevant and accounted for 348 articles, with keywords referring to risk, hazard, disease, and contamination. It is an important attribute in terms of public health, justifying the high number of published articles. Moreover, it can be measured using physical-chemical and microbiological analysis that indicate the presence of compounds or micro-organisms that can cause food-borne illnesses.

According to Grunert (2006), while food intake is influenced by attributes such as sensory, health, and safety as previously described, it is still strongly affected by cost. In this analysis, articles regarding the cost of food products were included in the "willingness to pay" topic, which contained 329 articles, making it the fourth most 
A bibliometric study on consumer behavior in the Food Science and Technology field $\mid 79$

Table 1: Journals of greatest relevance in the field of research

\begin{tabular}{|c|c|c|}
\hline Journal & IF (5 year) & Number of articles \\
\hline Food Quality and Preference & 3,227 & 251 \\
\hline British Food Journal & 1,069 & 201 \\
\hline Journal of Food Science & 2,182 & 139 \\
\hline Meat Science & 2,901 & 104 \\
\hline Journal of Sensory Studies & 2,143 & 100 \\
\hline Journal of the Science of Food and Agriculture & 1,983 & 70 \\
\hline Food Policy & 2,951 & 62 \\
\hline Postharvest Biology and Technology & 3,014 & 44 \\
\hline Food Research International & 3,535 & 41 \\
\hline International Journal of Food Science and Technology & 1,504 & 41 \\
\hline Journal of Dairy Science & 3,08 & 39 \\
\hline Journal of Agricultural and Food Chemistry & 3,387 & 33 \\
\hline Food Control & 3,038 & 30 \\
\hline Journal of Food Quality & 0,778 & 30 \\
\hline Journal of Food Agriculture Environment & 0,48 & 27 \\
\hline Agribusiness & 0,981 & 23 \\
\hline LWT Food Science and Technology & 3,107 & 23 \\
\hline Food Chemistry & 3,867 & 22 \\
\hline Journal of Food Protection & 1,974 & 20 \\
\hline Innovative Food Science Emerging Technologies & 3,59 & 19 \\
\hline Trends in Food Science Technology & 5,5 & 18 \\
\hline Ciencia e Tecnologia de Alimentos & 0,646 & 17 \\
\hline Italian Journal of Food Science & 0,309 & 17 \\
\hline Acta Alimentaria & 0,421 & 15 \\
\hline European Food Research and Technology & 1,818 & 14 \\
\hline Journal of Food Processing and Preservation & 0,778 & 14 \\
\hline Fleischwirtschaft & 0,091 & 13 \\
\hline Journal of Muscle Foods & 0,65 & 13 \\
\hline Food Technology & 0,854 & 12 \\
\hline Journal of Texture Sciences & 1,28 & 12 \\
\hline Cereal Chemistry & 1,388 & 11 \\
\hline Food Australia & 0,253 & 11 \\
\hline Journal of Food Science and Technology Mysore & 0,6 & 11 \\
\hline Milchwissenschaft Milk Science International & 0,36 & 11 \\
\hline Agro Food Industry High Tech & 0,23 & 10 \\
\hline Food Science and Technology International & 1,301 & 10 \\
\hline International Journal of Food Sciences and Nutrition & 1,322 & 10 \\
\hline Journal of Food Engineering & 2,984 & 10 \\
\hline
\end{tabular}

Table 2: Classification of hot topics according to keywords

\begin{tabular}{ccc}
\hline Hot topic & Keywords or Terms & Number of publications \\
\hline Sensory & Sensory, taste, flavor, odor, texture & 980 \\
Health & Health, diet, obesity nutrition, functional food & 614 \\
Safety & Safety, risk, hazard, disease, contamination & 348 \\
Willingness-to-pay & Willingness-to-pay, price, cost & 329 \\
Packaging & Packaging, label, food label information & 239 \\
Ethics & Ethics, biotechnology, genetically modified, organic, animal welfare & 208 \\
Lifestyle & Lifestyle, convenience, fast food, fresh food, natural & 196 \\
\hline
\end{tabular}

IJFS | April 2016 | Volume $5 \mid$ pages 73-83 
$80 \mid$ Kasemodel et al.

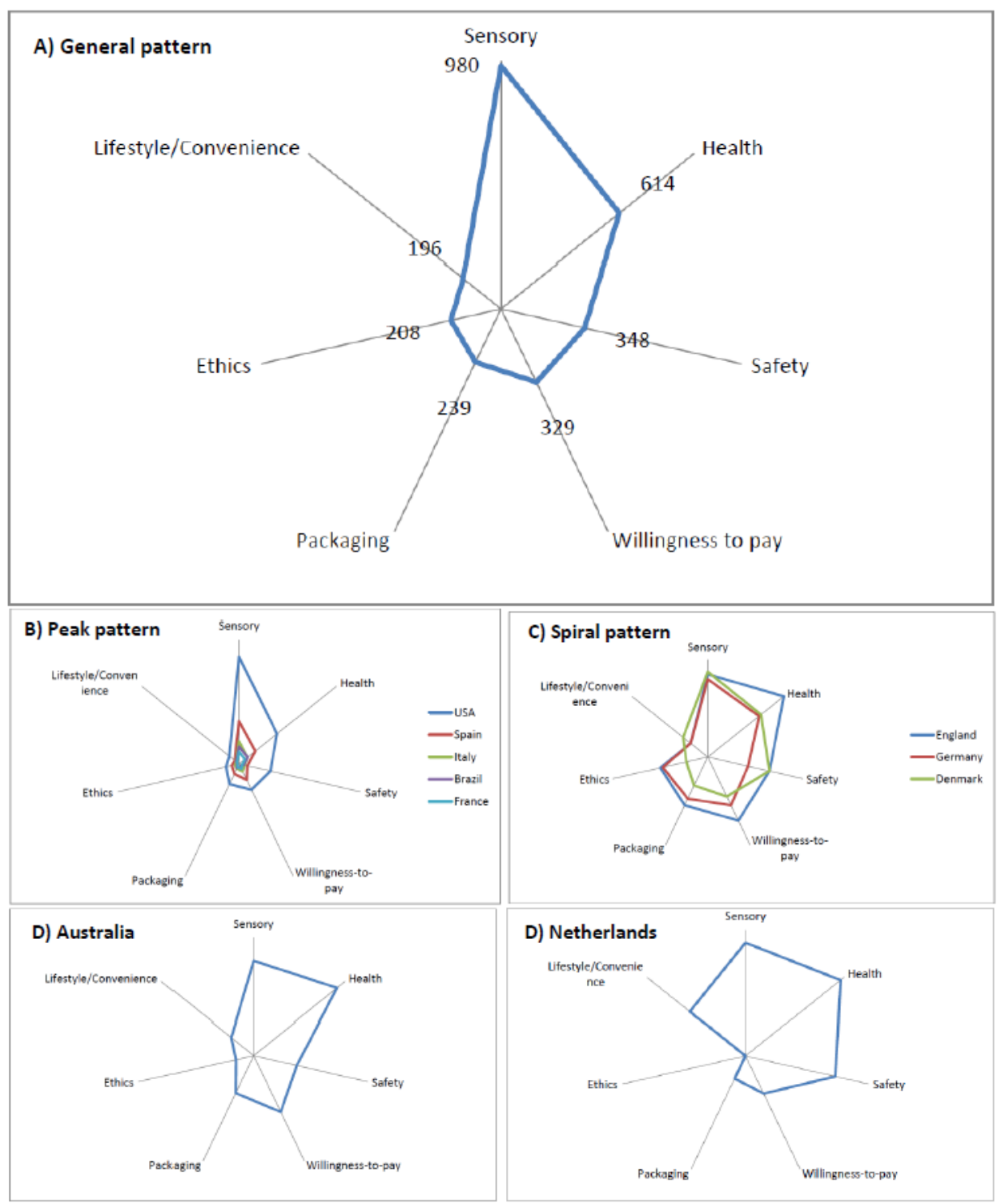

Figure 5: Hot topics

IJFS | April 2016 | Volume 5 | pages 73-83 
relevant in terms of volume.

The "packaging" topic ranks fifth and contained 239 articles related to the wrapping of food products, whether the technology or materials used or the information contained in labels. The study of this category is an important tool and can be used to promote sales of a particular product, or attract the consumer. Results are measurable through sensory analysis. It is worth noting that in terms of packaging, industrial research and product launches are mainly focused on marketing the same product in different portion sizes, characterizing an area of study with little innovation.

The "ethics" topic took sixth position, and contained 208 articles, with keywords regarding biotechnology, genetically modified organisms, organic food, and animal welfare. It was associated with food processing, since consumers seek products compatible with their personal values (Grunert, 2006). The increase in income associated with greater educational levels created consumers who are more concerned with issues such as animal welfare, genetically modified food, organics, use of recyclable materials, and waste reduction. Furthermore, the growing consumption of foods perceived as ethical is also due to their greater availability (Vermeir \& Verbeke, 2006). The aging populations, reduction in family size, increasing urbanization, and greater participation of women in the workforce, have all contributed to an increased demand for more convenient foods, including individual portions, frozen goods, and ready-to-eat food and beverages (Jerger, 2012). This context justified the growing importance of the "lifestyle/convenience" topic, which totaled 196 articles and ranked seventh in the analysis, and showed that Food Science and Technology innovation led to the development of better convenience products obtained mainly through portioning and packaging foods. Finally, it is important to note that an article could be included in more than one of the previously mentioned hot topics, and that the sum of articles found containing all hot topics $(2,914)$ is greater than the total number of articles analyzed $(1,786)$. For instance, a given article can be related to sensory attributes of a food as well as functional components that promote health, and thus be classified in both sensory and health hot topics; or an article may examine a convenient form of packaging, and thus be counted in both the convenient and packaging hot topics, causing an overlap.

Figure 5 presents a general pattern of hot topics in reference to global scientific production that categorized all seven hot topics according to the ten countries with the highest number of articles, as presented in the last section. This analysis made it possible to verify whether or not the study of consumer behavior in the field of Food Science and Technology can be considered homogeneous for different countries.

This analysis led to two clusters that are referred to as the 'peak' and 'spiral' patterns, represented in Figure 5. The peak pattern included USA, Spain, Italy, France, and Brazil, while the spiral pattern referred to England, Germany, and Denmark. Australia and the Netherlands did not display similar behavior, and were therefore evaluated separately.

The peak pattern was characterized by the considerably higher number of articles in the sensory hot topic when compared to the other six, therefore forming a notable peak in the graph. Countries in this pattern presented results corresponding to the general pattern, as the sensory hot topic prevailed as the most relevant in terms of volume. USA, Spain, and Italy reflect global analysis due to their quantitative importance, as they account for over $44 \%$ of articles. France and Brazil presented similar results, so that the sensory hot topic is of considerably greater relevance.

Countries in the spiral pattern were grouped because their graphs displayed similar behavior, due to the fact that England, Germany, and Denmark presented a considerably greater number of articles exhibiting the sensory, health, and willingness-to-pay hot topics, than ethics and lifestyle/convenience, thus creating a spiral form. For Australia, health was the hot topic of greatest importance in terms of volume of articles, followed by sensory and willingness-to-pay. Safety and packaging presented equal importance, while lifestyle/convenience ranked sixth, and ethics was the hot topic with the least number of articles.

In the Netherlands, health was considered the most relevant hot topic, followed by sensory 
and safety. Anomalously, lifestyle/convenience came in fourth in terms of volume of articles, surpassing willingness-to-pay, packaging, and ethics, whereas globally and for most countries lifestyle/convenience was found in the least number of articles.

\section{Conclusions}

The systematic analysis of 1,786 articles highlighted seven main hot topics: sensory, health, safety, willingness to pay, packaging, ethics, and lifestyle/convenience. It is relevant to note that the study was restricted to articles with explicit mention of consumer behavior, which in practice resulted in disregarding articles that were not explicitly related to consumer behavior, even if they addressed the hot topics identified.

Additionally, the comparison between countries showed that the development of this theme was not homogeneous. This finding demonstrated that technology and development do not occur in a vacuum. There are economic, cultural, political-legal, and capabilities (resources and skills) issues that are particular to each country. Intrinsic contexts that suggest trails become too specific.

Finally, bibliometric study methodology has been proven helpful in quantifying literature and evaluating emerging concepts (hot topics), allowing one to find trends regardless of the field of interest. With this in mind, bibliometric studies have wide potential future applications for different - and new - questions.

\section{Acknowledgements}

The authors would like to thank the Center for Organization Studies (www.cors.usp.br) for providing a rich environment for the development of this research. Our sincere thanks also to Girlei Aparecido de Lima for his contribution regarding the development of the methodology, as well as to Sarah Diane Eck for the initial inspiration. Last but not least, our sincere thanks to Prof. Alberto Sereno; whose comments have helped us improve the paper.

\section{References}

Aguilera, J. M. (2006). Seligman Lecture 2005 - Food product engineering: Building the right structures. Journal of the Science of Food and Agriculture, 86(8), 1147-1155. doi:10.1002/jsfa.2468

Bruin, S. \& Jongen, T. R. G. (2003). Food process engineering: the last 25 years and challenges ahead. Comprehensive Reviews in Food Science and Food Safety, 2(2), 42-81.

Chen, C. M. (2004). Searching for intellectual turning points: Progressive knowledge domain visualization. Proceedings of the $\mathrm{Na}$ tional Academy of Sciences, 101 (suppl 1), 5303-5310.

Chen, C. M. (2006). CiteSpace II: Detecting and visualizing emerging trends and transient patterns in scientific literature. Journal of the American Society for Information Science and Technology, 57(3), 359377. doi:10.1002/asi.20317

Gall, E., Millot, G., \& Neubauer, C. (2009). Faiblesse de l'effort français pour la recherche dans le domaine de l'Agriculture Biologique: approche scientométrique. Carrefours de l'Innovation Agronomique, 4, 363-375.

Grunert, K. G. (2006). How changes in consumer behaviour and retailing affect competence requirements for food producers and processors. Economia Agraria y Recursos Naturales, 6(11), 3-22. Retrieved from http:// aeea.webs.upv.es/aeea/ficheros/Revistas/ EARN-6\%201/01\%20Gruner.pdf

Jerger, C. (2012). Brazil's food and beverage market report. Zurique: OSEC Business Network Switzerland. Retrieved from http: //www.s-ge.com/en/filefield-private/files/ 43077 / field_blog_public_files/22183

Presoto, A. E., Souza, R. d. C., \& Thurler, J. H. F. (2013). Um estudo bibliométrico sobre cadeias de suprimentos sustentáveis. In Encontro nacional de engenharia de produção-enegep, XXXIII./national meeting of production engineering, XXXIII. 
A bibliometric study on consumer behavior in the Food Science and Technology field 83

(pp. 1-18). Associação Brasileira de Engenharia de Produção-ABEPRO.

Thanuskodi, S. (2010). Journal of social sciences: a bibliometric study. Journal of Social Sciences, $24(2), 77-80$.

Vermeir, I. \& Verbeke, W. (2006). Sustainable food consumption: exploring the consumer "attitude - behavioral intention" gap. Journal of Agricultural \&s Environmental Ethics, 19(2), 169-194. doi:10 . 1007/s10806-005-5485-3 